\title{
Probable Pathological Gambling Behaviors in Macau: Social Cognitive Theory Approach
}

\author{
Sao U. Chan \\ Independent Scholar, Macao \\ Luis Miguel Dos Santos \\ Independent Scholar, Macao
}

Received: March 20, 2018 Accepted: September 29, 2018 Published: October 1, 2018

doi: 10.5296/jsss.v6i1.12844ＵRL: http://doi.org/10.5296/jsss.v6i1.12844

\begin{abstract}
Probable pathological gambling is one of the significant social issues after the release of the exclusive and monopoly system of gambling licenses from one owner to three casino operating concessions and eventually six sub-concessions in Macau. As a result, some residents in Macau had addicted to gambling behaviors and eventually became probable pathological gamblers. In fact, why these individuals become probable pathological gamblers and how did they become probable pathological gamblers should be identified to enhance the current social policy and regulations to assist and provide support to these people. This study employed the Social Cognitive Theory to explore the lived experiences and opinions from three ex-probable pathological gambling people in Macau. The result of this study aimed to provide and attract the attention of the social welfare department, policy makers, social workers and counselors in the field of gambling addiction.
\end{abstract}

Keywords: Casino, Macau, Probable pathological gambling, Social cognitive theory

\section{Introduction}

Gambling is considered an illegal industry based on the current law and policy in mainland China. However, Macau, as a Special Administrative Region in China, is allowed to exercise and operate gambling casinos and hotels under the "One Country Two System" Principle. In fact, under the "One Country Two System" Principle, the Macau Special Administrative Region government has the rights to decide either or not the casinos may continue its operation after the transfer of sovereignty over Macau from the Portuguese government to the 
Chinese government during the late 1999s. As gambling industry has been the primary economy in Macau for nearly a century since the Portuguese colonial leadership, the Macau Special Administrative Region government does not have any intentions to eliminate the gambling industry after the transfer in 1999 (Kuok \& Dos Santos, 2017).

In 2002, the Macau Special Administrative Region government decided to release the exclusive and monopoly system of gambling licenses from one owner to three casino operating concessions and eventually six sub-concessions. After the rapid economic development due to the gambling and tourism industries, a large number of local residents are employed within these industries. Besides the positive aspects, such as the economic growth, international reputations, and the increase of living standards, the negative aspects, such as probable pathological gambling behaviors and related addictions have become one of the clinical and social problems in Macau (Fong, Fong, \& Li, 2011).

As the gambling industry is the leading field in Macau, a large number of residents, including but not limited to housewives, high school graduates, university graduates, dropped out students, had entered the gambling industry due to the attractive salary. However, there is an obvious potential that casino workers may associate with problematic gambling. In addition to the physical casino environment, internet, online, and visual gambling channels are not uncommon in Macau. As for such visual casino smartphone applications and online casino websites, underage juniors, high school students, university students, and minorities may have easy access due to the lower security checking. As a result, juniors and minorities may have the opportunities to interact with gambling during their early age and eventually develop as problematic gambling additions (Gu \& Gao, 2006; Wu \& Hsu, 2015).

\subsection{Aim and Objectives}

The study investigates the probable pathological gambling behaviors in Macau. Analyzing the contemporary social problems toward problematic gambling behaviors and what type(s) of factors may influence the gambling behaviors from the perspectives of ex-probable pathological gambling person. This study can increase the awareness of policymakers, social workers, government agencies, leadership at NGOs, and scholars who want to understand more about the overall dynamic of the gambling industry in Macau.

In fact, as probable pathological gambling is not a common mental illness in most of the countries in the world, a significant amount of social workers and counselors may not have the experience and background handling such social problems. Therefore, the results of this study provide the appropriate personnel with practical suggestions.

Based on the ideas about collecting perspectives and opinions from ex-probable pathological gambling person in Macau, this study was followed by one research question, which is: 1) what type(s) of factors may influence the gambling behavior of probable pathological gamblers to start their gambling habit at the first place?

\subsection{Theoretical Framework}

This study employed the Social Cognitive Theory (Bandura, 1986) to investigate the factors that may influence the gambling behaviors. This theory advocates that individuals and groups may learn specific behaviors by observing others from the society. Three significant elements that individuals can gain knowledge are human being, behaviors, and environment. These 
elements can interact and engage with each other to influence the decision making of individuals. However, no single element can influence the decision as individuals may be influenced by different factors based on location, time, setting, etc.

\section{Literature Review}

\subsection{General Problems of Probable Pathological Gambling}

Excessive addition to gambling behaviors can cause personal, family, personal, economic, work and social problems. Loss of self-esteem, loss of friends, commit crimes, unemployment, poverty, hunger and family breakdown are some of the social problems that are caused by probable pathological gambling behaviors. Besides physical and external activities, depression, anxiety, anger, neglect, and ideas of suicide are also found in many of the cases of probable pathological gambling. With the combination of both internal and external activities, individuals and families may have the opportunities to associate with divorce, suicide, bankruptcy, criminal activities (Tse, 2006).

According to Ping Wo Fund (2017), a research project has pointed out that the negative impacts of probable pathological gambling behaviors are horrendous s. It does affect not only the pathological gamblers, but also their spouse and families. The research finding indicated that some gamblers might associate with debt (HKD 2,000 to HKD 3,000,000) and even bankruptcy, negative and broken relationships, divorce, poor relationship with children, isolation of social networks, fired by an employer, mental disorder, and frustration at work. The most common impact of probable pathological gambling behaviors on families is the financial constraints on the part of the family. Some families even need to consume all the family and personal saving as a result of assisting gambling debts.

New media is one of the most developed and applicable within the contemporary society. All industries, including but not limited to hospitality, retailed, educational institutions, NGOs, and government agencies, have developed internet websites and smartphone applications to attract potential customers who would like to gain accesses to their services. Gambling and casino industries also developed such new media applications. Besides the traditional telephone betting, betting via internet websites, smartphone, and online applications, may create another social problem. In fact, under the current law and policy in Macau, individuals under the age of 21 are not allowed to associate with any types of gambling activities. However, as teenagers are more easy to download and search gambling websites and applications via the internet, juniors and underage residents may have the chances to encounter with gambling activities. Besides the traditional gambling environment with different groups and parties, internet and online gambling activities do not require more than one person. In other words, teenagers and underage juniors may associate with gambling activities without any interactions. Therefore, parents, social workers, teachers, and peers may not be able to diagnosis the underage gambling activities immediately (King et al., 2010).

In conclusion, probable pathological gambling may impact a large number of aspects besides individual level, the family members, friends, peers, and co-workers of the gamblers. 


\subsection{The Cause of Probable Pathological Gambling Behaviors in Macau}

\subsubsection{The Change of Understanding}

Gambling is easily involved. Gambling is based on the idea of gaming. Gambling is a combination of greedy objects, the competition of intelligence, and the training of logical thinking with a repeated excitement. Human being tends to compete with others. The joy of winning meet the subconscious and the real pleasure of humanity, which is the long-term psychological reason for gambling. Besides the traditional gambling games, such as mark-six, slot machines, soccer gambling, and card games, online and internet gambling channels are easy to be accessed outside of the casino environment. Also, as the Macau Special Administrative Region government decided to release the exclusive and monopoly system of gambling licenses from one owner to three casino operating concessions and eventually six sub-concessions in 2002, a large number of residents in Macau started to believe gambling is a social and interactive activity among friends and peers. In the aspect of employment, a significant number of local residents also entered the gambling and hospitality industry after 2002. Based on the environmental and economic factors, a reasonable amount of local residents may addict with probable pathological gambling behavior (Tze, 2007).

\subsubsection{Casinos Within the Residential Community}

Unlike the Las Vegas and other international cities with casino facilities, all the casinos and slot machine gaming facilities are located within the residential community. One of the negative impacts of casinos located in a residential community is that children, juniors, teenagers, and underage people may have access to these locations during their young age. In fact, when juniors have the chance to interact with gambling activities and facilities during their early age, there would be a higher chance that they may associate with gambling activities during early adulthood. According to Abbott, Cramer and Sherrets (1995), as many people started to accept gambling as a social interaction instead of negative behavior from year to year, the demands of casinos and gambling facilities were much higher than the mid- $20^{\text {th }}$ century. Cox et al. (2005) indicated that slot machines and traditional casino are two of the locations where people are easy to addict probable pathological gambling behaviors. As residents are easy to access to high risked gambling activities within the residential community, the relationship between addiction of probable pathological gambling behaviors and convenience to access to casinos and gambling facilities would be proportional. Therefore, probable pathological gambling behaviors could be considered as the side-effect of the casinos (Shaffer, Hall, \& Vander, 1999; Volberg, 1994).

\subsection{The Overview of Probable Pathological Gambling Behaviors in Macau}

\subsubsection{Social Cost of Probable Pathological Gambling}

In the early 2000 s, more than $70 \%$ of local residents in Macau had associated with at least a type of gambling activity. Within these populations, nearly 14,000 (4.3\% of the total population) of the local residents were considered as probable pathological gamblers (Fong \& Ozorio, 2005). In fact, $4.3 \%$ of the total population was not a significant amount of residents. However, each of the probable pathological gamblers may have the chance to influence up to 17 family members, friends and peers in a row (Leiseur, 1989). Based on the potential calculation and recommendation from Leiseur (1989), more than $40 \%$ of the local residents 
may face different levels of problems with probable pathological gambling.

As for the probable pathological gamblers, it can be considered as social costs. It is evident that the social costs are the criminal justice costs created by gambling crimes. In addition to the costs in the justice department, addiction counseling and family therapies are also considered as direct costs to the society due to probable pathological gambling. Research indicated that probable pathological gambling might cause the following social costs: 1) justice costs; 2) crimes; 3) decrease of working hours and work effectiveness; 4) unemployment; 5) bankruptcy; 6) suicide; 7) health issue; 8) family issue; 9) personal financial difficulties; and 10) accident (Tze, 2007). According to the number of gambling, crimes have been increased significantly from 2002 to 2008. Chart 1 indicates the overall number of gambling crimes from 2002 to 2008.

The Statistics of Gambling Crimes from 2002 to 2008

\begin{tabular}{llllllll}
\hline Year & 2002 & 2003 & 2004 & 2005 & 2006 & 2007 & 2008 \\
\hline Crime Number & 314 & 414 & 823 & 1093 & 979 & 1279 & 1506 \\
\hline
\end{tabular}

Based on the above statistics, the number of gambling crime has been increased significantly. As such numbers have been increased, the related social costs were increased based on these numbers. In fact, the data did not reflect the background and nationalities of the criminals. Therefore, no actual statistics may indicate either or not local residents committed gambling crimes.

\subsubsection{How to Do Visual, Online, and Internet Gambling Influence Gamblers}

In the Chinese society, social gambling is considered as an acceptable and reasonable activity. When gambling activities are able to be assessed online, juniors, teenagers, high school students, and university students are able to participate in the games quickly. The researcher has concluded the reasons in three directions (Tao et al., 2011).

First, in the traditional Chinese society and expectations, Chinese people believe filial piety is one of the keys for younger generations to follow. Therefore, educators within the secondary school levels believe teenagers would like to gain self-authorities puberty developmental progress. As the internet and online gambling websites are one of the best sources to gain self-controls outsides of the controls from parents. Therefore, teenagers and young adults are more likely to become gamblers. On the other hands, parents, particularly for low-income parents and single parents, believe computers and internets are the critical items for new learning techniques and skills. Therefore, parents usually agree and encourage their children to learn new knowledge from the internets.

Second, parents believe their children should stay at home for learning and study. Some parents believe instead of interacting with friends outsides of the school environment, staying at home with computers and internets learning could be much safer. Therefore, some parents believe computers and internets are the essential items to engage their children to stay at home and study. In other words, some parents believe computers and internets are the tools for social and behavioral control of their children. 
Third, the information technology skills differences. Based on the well-designed curriculum development of schools, most of the secondary school and university students have gained the most updated information technology and computers skills after the school graduation. It is not surprising that a large number of university students may have better information technology and computers skills than their parents. As a result, parents may not be able to prohibit or control the gambling behaviors and gambling interactions within the internets of their children.

\section{Methodology}

This study employed a qualitative research methodology to collect lived experience of three ex-probable pathological gambling person in Macau. The tool for this study was the Interpretative Phenomenological Analysis (IPA), which explore and summarize how people make sense of their personal, social and lived experience within the lifespan (Smith, Flowers, $\&$ Larkin, 2009). The following illustrated the biography of the three participants of this study.

\begin{tabular}{lllll}
\hline Name & Age & $\begin{array}{l}\text { Years of Suffer from the Probable } \\
\text { Pathological Gambling Behavior }\end{array}$ & $\begin{array}{l}\text { The Age to Start } \\
\text { Gambling Behaviors }\end{array}$ \\
\hline Alan & 30 & 10 & 15 \\
Benson & 28 & 8 & 13 \\
Catherine & 25 & 8 & 10 \\
\hline
\end{tabular}

The researchers were the primary tools for the data collection and analysis processes. In order to collect meaningful information for this study, the researchers conducted the semi-structured and face-to-face interview with the participants. The semi-structured interviews were hosted between 80-120 minutes within a private space in one of the public library locations in the city. All the interview sections were digitally recorded with a cellphone. As all of the participants' native language is Chinese Cantonese, in order to report all the data into an international peer-reviewed journal, the researchers first transcribe all the Chinese recording into a written transcript. Afterward, the researchers have translated the Chinese written transcript into the English language for data analysis (Dos Santos, 2016; Tang \& Dos Santos, 2017).

In order to categorize all the data information into meaningful research themes, the researchers have followed the opening coding and axial coding procedures to narrow down all the written information into three themes.

In addition to the data collection procedures, protecting human information is one of the priorities for this study. Therefore, the researchers have stored all the personal information, including sound recording, transcripts, agreements, invitation letter, research data, and all related documents and items into a password-protected computer. For physical items, including the computer, were locked into a password-protected locker for storage. 


\section{Finding}

The results revealed three themes, which were mentioned in each of the narratives. However, these themes were experienced in similar or different ways by the participants. In addition to the establishment of themes, it is worth to note that the establishment of themes was echoed with the direction of Social Cognitive Theory (Bandura, 1986).

The themes were: 1) parental influence of gambling; 2) the convenient access to gambling locations; 3) social gambling with peers and friends.

\subsection{Parental Influence of Gambling}

All of the participants expressed that the gambling behaviors of their parents were profoundly influence their gambling behaviors and understanding during their early childhood. Three of the participants' parent(s) were working in the casino setting. Therefore, casino, gambling, and lottery money have occupied significant spaces in their childhood. Alan said,

My dad is a casino dealer from the early 1990s. He always practiced how to play the casino games at home. Sometimes, he asked my brother, my sister and I to play and exercise the games with us. Three of the children always acted as the customers, and my dad was the dealer. This was the first time I interacted with casino games.

Like Alan, Benson's mother also worked in the casino during their early childhood. Benson's mother did not practice any casino games in front of him. However, his mother always shared how tips money can be quickly earned in the casino, said,

I still remembered my mom always told me tips could be earned every night. She could make up to MOP 5,000 MOP (around USD 600) per night. This money was almost equaled to a monthly salary of an office worker in the banking industry. So I would like to enter the casino once I reached the age.

Catherine also had the similar family background. Both of her parents worked in the casino industry since her birth. Also, all of their family friends and even relatives were casino workers as well, said,

My parents both are still working in the casino as gaming managers. In addition to my parents, several of my uncles and aunts are casino dealers and supervisors as well. This is not uncommon for the situation in Macau. As most of our family friends and relatives are casino workers, our family discussions and expectations are all about gaming and money.

All of the participants' parents and even family relatives were all working in the casino setting. Therefore, the early childhood and teenage of participants usually involved with ideas and discussion topic about gambling and casino games. Besides the experience of early childhood and teenage, all participants were encouraged to enter the casino industry after their secondary school graduation. Catherine said,

After I completed my $11^{\text {th }}$ grade, my parents immediately encourage me to enter the casino industry after the final year of secondary school. As the elder sister of my family, I would like to earn some resources to release the financial pressure of my family. Therefore, I decided to work as a dealer after secondary school graduation. This is also the first time I started my gambling behavior.

Benson also had a similar situation as Catherine said, 
My parents also told me casino is the place for residents to make money and become a useful person. That is why I decide to join this direction. I just graduated from secondary school without much social experience. As my parents can refer me to the casino, so I went there without much consideration.

Alan's parents did not intend to encourage him to join this industry but decided to enter by himself, said,

I saw my parent can make much money than other uncles and aunts. Working as a bank teller could not even make half of the salary of a casino dealer. Therefore, as I would like to work as a successful person as my parents, so I decided to work as a casino dealer after secondary school.

\subsection{The Convenience Access to Gambling Locations}

Unlike other international and large urban cities, the administrative area of Macau is extraordinarily tiny and narrow. In other words, the location of casinos and residential communities are interweaved with each other. Therefore, all residents including students and children can easily to access any of the casinos and gambling center within the community. Therefore, children and students may gain the senses of gambling, lottery, and casino games on the way to schools. Alan shared,

Within my community, there are four casino buildings, two or three gambling centers, and a dance club. At night, I could see much building lights and visitors on the street talking about gambling. As I grew up in such environment, I would like to enter the casino and see how beautiful it is.

Catherine's apartment is right located above a gambling center for international soccer games, said,

There were always more than 50 gamblers staying near my apartment every day from day to night. I heard much chatting about soccer games in England, Argentina, and Portugal from my early age. My dad is a soccer gambler as well. He sometimes brought me to the gambler center for lottery ticket purchasing as well. Even if I just stayed outside of the gambling center as I was underage, but I could understand the nature of soccer gambling.

Similarly, Benson's secondary school and apartment were right in front of a casino building. All of his childhood and teenage were all about casino as well, said,

The casino front entrance is facing the front entrance of my secondary school. There is no way that the classmates can skip the smiling faces from the gamblers in that casino. Our teacher always encouraged us not to look at the casino. However, none of the secondary school students would listen to such suggestions. After we graduated from secondary school and reached the age of 18 , all of our classmates went to that casino with our uniform.

In fact, as the residential area and gambling facilities are interwoven with the daily life of residents in Macau. There could be a high potential for non-gamblers and underage people to interact and learn the gambling behaviors based on daily observations. As gambling is highly engaged with the life practice of residents, it is not hard to believe gambling behaviors could be gained based on this situation. 


\subsection{Social Gambling with Peers and Friends}

Three of the participants also expressed that social gambling with classmates and friends are not uncommon in Macau as most of the people could play casino games within their friend-groups. Benson said that he had played Mahjong with his classmates after school during his high school period, said,

Several of our classmates always played Mahjong and poker after school time almost every day without stopping. In the first month, we did not gamble any money. However, we did eventually. It is very common for secondary school students to play gambling games in Macau.

Catherine also expressed a similar situation as Benson's said,

Other three girls and I had formed a small girl's group in $11^{\text {th }}$ grade. One of the major gatherings for this girl's group was to play poker and gambling during the weekend at someone's apartment. Sometimes, my friend's parents also joined us to play Mahjong. As adult also encouraged us to play, we did not see anything wrong with gambling.

Alan also had a similar situation, said,

I had a good classmate who was the neighbor living next to us. We always played Mahjong and poker after dinner. His family always played Mahjong after dinner and encouraged me to play as well. Once I finished my homework, my mom usually agreed for going.

\section{Discussion and Conclusion}

Based on the research objective and aim of this study, the researchers explore the gambling behavior of three probable pathological gamblers in Macau and understand the factors that may influence their gambling behaviors. The study followed one research question as the guideline, which is: 1) what type(s) of factors may influence the gambling behavior of probable pathological gamblers to start their gambling habit at the first place? In addition to the research question, this study also employed the Social Cognitive Theory (Bandura, 1986) to explain the behaviors, activities, and factors that may influence the decision-making process of individuals.

First, it is worth to note that all participants believed the behaviors of their parents, peer, and friends had significant connections with their gambling behaviors. Three themes have been categorized, which were: 1) parental influence of gambling; 2) the convenient access to gambling locations; 3) social gambling with peers and friends. All of these participants had their parents working in the casino or related location. As their parents usually shared and practice casino games and topics with them, all of them had observed the gaming practice and understood the operations within the casino environment. As all these participants were growing up within such gambling environment, they had developed a habit and understanding about gambling and making money in the casino.

Second, as the community of Macau is relatively tiny. Therefore, some casino facilities and gambling centers were established within the residential area and even next to some community establishments, such as schools and living quarters. Therefore, it is not hard for children, teenagers, and students to observe and learn casinos and gambling in their early age. According to Bandura (1986), individuals, particularly for children, may easily absorb behaviors and knowledge from parents, teachers and other peers based on observation. In 
addition, as children and students believed that gamblers could gain reward and money from the casino and gambling centers, in order to gain such rewards by themselves, going to casino could be the best way. Therefore, based on the observations from others, these probable pathological gamblers had observed and absorbed the gamblers' behaviors from their daily observations.

Third, social gambling is not regulated by any laws and policies. Unlike casino games, such as Blackjack, Mahjong, poker cards, and dice games are generally standard in the daily practice in the Chinese communities and societies. As most of the Chinese families do not discourage their underage children to play these games after school, a few individuals may start to engage with gaming and gambling in their teenage and early adulthood. As several individuals may observe such gaming and gambling behaviors in their early age, they may gain the senses of gambling and eventually become their daily practice and behavior.

In conclusion, based on the data information from the participants with the guideline of Social Cognitive Theory (Bandura, 1986), the researchers explored how gambling behaviors could engage with early age observations from families, peers, and friends within their daily life and practice. In fact, Bandura advocated that individuals usually observe others' behaviors and practices in order to achieve the similar rewards and awards from others. On the other hand, after the observations, individuals also understood how to avoid non-favorable activities and behaviors for punishments. In this study about the probable pathological gambling behaviors in Macau, it is worth to note that all of these participants expressed that observing others' behaviors were the critical elements for gaining such behaviors within their early adulthood. As a result, this study could serve as a reminder for social welfare department, government agencies, NGOs, policymakers, and counselors to re-design the urban planning, educational curriculum maps, social welfare policies, and related regulations in order to protect the young generations from gambling behaviors and activities.

\section{References}

Abbott, D. A., Cramer, S. L., \& Sherrets, S. D. (1995). Pathological gambling and the family: Practice implications. Families in Society: The Journal of Contemporary Human Services, 76(4), 213-219.

Bandura, A. (1986). Social foundations of though and action. Englewood Cliffs, NJ: Prentice Hall.

Cox, B. J., Yu, N., To, A., \& Ladouceur, R. (2005). A national survey of gambling problems in Canada. Canadian Journal of Psychiatry, 50(4), 213-217. https://doi.org/10.1177/070674370505000404

Dos Santos, L. M. (2016). Relationship between turnover rate and job satisfaction of foreign language teaches in Macau. Journal of Educational and Development Psychology, 6(2), 125-134. https://doi.org/10.5539/jedp.v6n2p125

Fong, D. K. C., Fong, H. N. F., \& Li, S. Z. (2011). The social cost of gambling in Macao: Before and after the liberalization of the gaming industry. International Gambling Studies, 11(1), 43-56. https://doi.org/10.1080/14459795.2010.548393 
Fong, D., \& Ozorio, B. (2005). Gambling participation and prevalence estimates of pathological gambling in a Far-East gambling city: Macao. UNLV Gaming Research \& Review Journal, 9(2).

Gu, Z., \& Gao, J. Z. (2006). Financial competitiveness of Macau in comparison with other gaming destinations. UNLV Gaming Research \& Review Journal, 10(2).

King, D., Delfabbro, P., \& Griffiths, M. (2010). The convergence of gambling and digital media: Implications for gambling in young people. Journal of Gambling Studies, 26(2), 175-187. https://doi.org/10.1007/s10899-009-9153-9

Kuok, W.S., \& Dos Santos, L.M. (2017). Understanding of the establishment and importance of public relations department in Macao: Perspectives from governmental officials. Journal of Public Administration and Governance, 7(3), 14-29. doi:10.5296/jpag.v7i3.11384

Lesieur, R. H. (1989). Current research into pathological gambling and gaps in the literature. In H. Shaffer (Ed.) Compulsive Gambling: Theory, Research \& Practice (pp. 225-248). Lexington Books, Toronto.

Ping Wo Fund. (2017). Report on the study of Hong Kong people's participation in gambling activities in 2016. Hong Kong: The Hong Kong Polytechnic University. Retrieved from http://www.hab.gov.hk/file_manager/en/documents/policy_responsibilities/others/gambling_r eport_2016.pdf

Smith, J., Flowers, P., \& Larkin, M. (2009). Interpretative phenomenological analysis: Theory, method and research. London, UK: Sage.

Tang, K. H., \& Dos Santos, L. M. (2017). A brief discussion and application of interpretative phenomenological analysis in the field of health science and public health. International Journal of Learning and Development, 7(3), 123-132. https://doi.org/10.5296/ijld.v7i3.11494

Tao, V. Y. K., Wu, A. M. S., Cheung, S. F., \& Tong, K. K. (2011). Development of an indigenous inventory GMAB for Chinese gamblers: An exploratory study. Journal of Gambling Studies, 27(1), 99-113. https://doi.org/10.1007/s10899-010-9191-3

Tse, W. L. J. (2006). Adolescent pathological gambling: Prevention and treatment. Hong Kong: Chinese University Press.

Volberg, R. A. (1994). The prevalence and demographics of pathological gamblers: Implications for public health. American Journal of Public Health, 84(2), 237-241. https://doi.org/10.2105/AJPH.84.2.237

Wu, H. C., \& Hsu, F. S. (2015). A multi-dimensional and hierarchical model of service quality in the gaming industry. International Journal of Tourism Sciences, 12(3), 90-118. https://doi.org/10.1080/15980634.2012.11434665

\section{Copyright Disclaimer}

Copyright for this article is retained by the author(s), with first publication rights granted to the journal.

This is an open-access article distributed under the terms and conditions of the Creative Commons Attribution license (http://creativecommons.org/licenses/by/3.0/). 